\title{
The efficacy of oral and subcutaneous antigen-specific immunotherapy in murine cow's milk- and peanut allergy models
}

\author{
Marlotte M. Vonk ${ }^{1,2 \dagger}$, Laura Wagenaar ${ }^{3 \dagger}$, Raymond H. H. Pieters ${ }^{3,4^{*}}$, Leon M. J. Knippels ${ }^{1,2}$, \\ Linette E. M. Willemsen', Joost J. Smit', Betty C. A. M. van Esch ${ }^{1,2}$ and Johan Garssen ${ }^{1,2}$
}

\begin{abstract}
Background: Antigen-specific immunotherapy (AIT) is a promising therapeutic approach for both cow's milk allergy (CMA) and peanut allergy (PNA), but needs optimization in terms of efficacy and safety.

Aim: Compare oral immunotherapy (OIT) and subcutaneous immunotherapy (SCIT) in murine models for CMA and PNA and determine the dose of allergen needed to effectively modify parameters of allergy.

Methods: Female $\mathrm{C} 3 \mathrm{H} / \mathrm{HeOuJ}$ mice were sensitized intragastrically (i.g.) to whey or peanut extract with cholera toxin. Mice were treated orally ( 5 times/week) or subcutaneously (3 times/week) for three consecutive weeks. Hereafter, the acute allergic skin response, anaphylactic shock symptoms and body temperature were measured upon intradermal (i.d.) and intraperitoneal (i.p.) challenge, and mast cell degranulation was measured upon i.g. challenge. Allergenspecific $\lg E$, IgG1 and lgG2a were measured in serum at different time points. Single cell suspensions derived from lymph organs were stimulated with allergen to induce cytokine production and T cell phenotypes were assessed using flow cytometry.
\end{abstract}

Results: Both OIT and SCIT decreased clinically related signs upon challenge in the CMA and PNA model. Interestingly, a rise in allergen-specific IgE was observed during immunotherapy, hereafter, treated mice were protected against the increase in IgE caused by allergen challenge. Allergen-specific lgG1 and IgG2a increased due to both types of AIT. In the CMA model, SCIT and OIT reduced the percentage of activated Th2 cells and increased the percentage of activated Th1 cells in the spleen. OIT increased the percentage of regulatory T cells (Tregs) and activated Th2 cells in the MLN. Th2 cytokines IL-5, IL-13 and IL-10 were reduced after OIT, but not after SCIT. In the PNA model, no differences were observed in percentages of T cell subsets. SCIT induced Th2 cytokines IL-5 and IL-10, whereas OIT had no effect.

Conclusion: We have shown clinical protection against allergic manifestations after OIT and SCIT in a CMA and PNA model. Although similar allergen-specific antibody patterns were observed, differences in T cell and cytokine responses were shown. Whether these findings are related to a different mechanism of AIT in CMA and PNA needs to be elucidated.

Keywords: Cow's milk allergy, Peanut allergy, Immunotherapy, Oral, Subcutaneous, Desensitization, Tolerance induction

\footnotetext{
*Correspondence: r.h.h.pieters@uu.nl

${ }^{\dagger}$ Marlotte M. Vonk and Laura Wagenaar contributed equally to this work

${ }^{3}$ Department of Immunotoxicology, Faculty of Veterinary Medicine,

Institute for Risk Assessment Sciences, Utrecht University, PO Box 80177,

3508 TD Utrecht, The Netherlands

Full list of author information is available at the end of the article
} 


\section{Background}

Food allergy is an important socio-economic health problem estimated to occur in $10 \%$ of pre-school children (Westernized countries) and 1-2\% of adult individuals (USA) [1, 2]. Two of the major allergenic foods, peanut- and cow's milk protein, show different disease patterns. Cow's milk allergy (CMA) is most prevalent during early childhood, but is often outgrown [3] while peanut allergy (PNA) is more persistent and is the most frequent cause of life-threatening allergic reactions in adults [4]. Unfortunately, current treatment options for food allergies are limited, being a strict elimination diet and self-administration of epinephrine in case of an anaphylactic response. The need for effective and safe therapeutic options has elicited intensive research into antigen-specific immunotherapy (AIT) as an active tolerance-inducing strategy.

One form of AIT, subcutaneous immunotherapy (SCIT), is effective and safe in respiratory allergies and insect venom hypersensitivities [5-7] and has been recognized as the gold standard immunotherapy method for decades [8]. However, to date, SCIT has not been used to treat food allergies due to the high incidence of severe side effects in two conducted peanut allergy trials $[9,10]$. The less invasive alternative, oral immunotherapy (OIT), has been shown to increase the threshold of food tolerated in a double-blind placebo-controlled food challenge (DBPCFC) in a majority of the subjects in several randomized placebo-controlled clinical trials when on therapy [11]. Nonetheless, OIT for food allergy is still an experimental therapeutic strategy because of the risk of side effects and accidental symptoms towards a previously tolerated dose. OIT in cow's milk- and peanut allergic children was accompanied by persistent adverse reactions during treatment $[12,13]$. In addition, sustained unresponsiveness to a food challenge after discontinuation of OIT has only been demonstrated in a minority of the subjects [14]. This clearly leaves OIT open for improvement in both therapy safety and efficacy.

Specific immunological aspects have been suggested to be involved in desensitization and the development of clinical tolerance, including a suppressed $\mathrm{T}$ helper 2 (Th2) cell response [11] and the induction of regulatory $\mathrm{T}$ cells (Tregs) [15-17], decreased antigen-specific IgE and increased antigen-specific IgG4 levels [18] and effector cell unresponsiveness [19] in mice and/or human. Further attempts to link immunologic changes induced by AIT to clinical protection have been made using murine models of egg allergy. The induction of long-term tolerance was unsuccessful, however, significant changes in intestinal gene expression were observed in clinically protected mice $[20,21]$. In humans, clinical tolerance was associated with hypomethylation of the forkhead box protein 3 (FoxP3) locus in Tregs [22].

The goal of this study was to compare the efficacy of OIT and SCIT and to determine the dose of allergen needed to effectively modify parameters of allergy in murine CMA and PNA models.

\section{Methods \\ Mice}

All animal procedures were performed according to governmental guidelines and approved by the Ethical Committee of Animal Research of Utrecht University, Utrecht, The Netherlands. Specific-pathogen free 6-week old female $\mathrm{C} 3 \mathrm{H} / \mathrm{HeOuJ}$ mice $(\mathrm{n}=6-8 /$ group $)$ were purchased from Charles River Laboratories (L'Arbresle Cedex, France) and were fed a peanut- and cow's milk protein-free standard mouse chow (AIN-93G soya, Special Diets Services, Witham, UK). The animals were housed at the animal facility of Utrecht University on a $12 \mathrm{~h}$ light/dark cycle with unlimited access to food and water.

\section{Reagents}

Peanut protein extract (PE) was prepared from raw peanuts (provided by Intersnack Nederland BV, The Netherlands) as described previously [23]. Concisely, protein was extracted from ground peanut by mixing $150 \mathrm{~g}$ of ground peanut with $750 \mathrm{ml}$ of $20 \mathrm{mM}$ Tris buffer (pH 7.2). After stirring every $10 \mathrm{~min}$ for $2 \mathrm{~h}$ at room temperature (RT), the aqueous fraction was collected after centrifugation $(3000 \times \mathrm{g}$ for $30 \mathrm{~min})$ and subsequently centrifuged at $10,000 \times \mathrm{g}$ for $30 \mathrm{~min}$ to remove residual traces of fat and insoluble particles. The extract contained $30 \mathrm{mg} / \mathrm{ml}$ protein as determined by Bradford analysis with Bovine Serum Albumin (BSA) as a standard. Whey protein powder was provided by Nutricia Research (Utrecht, The Netherlands). Cholera toxin (CT) was purchased from List Biological Laboratories Inc. (Campbell, CA, USA).

\section{Experimental design: oral sensitization, immunotherapy and challenges}

Mice were sensitized intragastrically (i.g.) to whey (20 mg in $0.5 \mathrm{ml} \mathrm{PBS})$ or PE (6 $\mathrm{mg}$ in $200 \mu \mathrm{l} \mathrm{PBS})$ using CT $(15 \mu \mathrm{g} /$ mouse) as an adjuvant $[23,24]$ (day $0,7,14,21$ and 28 for whey and day $0,1,2,7,14,21$ and 28 for PE) (Fig. 1). Sham-sensitized mice received CT in PBS alone. One week after the last sensitization (day 42), the mice were treated orally (OIT: $0.1,1,10$ and $100 \mathrm{mg}$ whey or $0.15,1.5$ and $15 \mathrm{mg}$ PE in $500 \mu \mathrm{l} \mathrm{PBS}$ ) for 5 times/week or subcutaneously (SCIT: 2.5, 10 and $25 \mu \mathrm{g}$ whey or 1,10 and $100 \mu \mathrm{g}$ PE in $200 \mu \mathrm{l}$ PBS) for 3 times/week, for three consecutive weeks (day 42-60). Sham-sensitized and allergen-sensitized control mice were treated i.g. with 


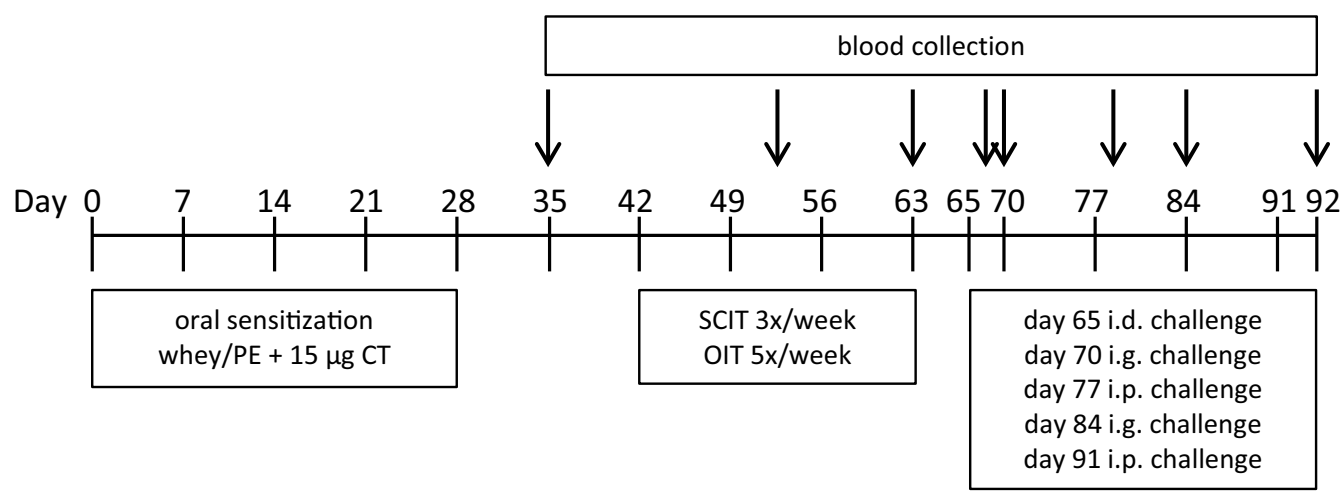

Fig. 1 Experimental set-up of PNA and CMA model. Mice were sensitized i.g. to whey, PE or PBS alone in combination with CT (day 0,7, 14, 21 and 28 for CMA and day $0,1,2,7,14,21$ and 28 for PNA). From day 42, the mice were treated orally for 5 times/week or subcutaneously for 3 times/week with allergen or PBS alone, for three consecutive weeks (day 42-60). On day 65, all mice were challenged i.d. to determine the acute allergic skin response, anaphylactic shock symptom scores and body temperature levels. On day 70 and 84, i.g. challenges were performed to measure mucosal mast cell degranulation. After i.p. challenges on day 77 and 91, anaphylactic shock symptom scores and body temperature levels were measured. At day 92, the mice were killed with cervical dislocation and blood and organs were collected. PE peanut extract, CT cholera toxin, SCIT subcutaneous immunotherapy, OIT oral immunotherapy, i.d. intradermal, i.g. intragastric, i.p. intraperitoneal

PBS alone. On day 65, all mice were challenged intradermally (i.d.) in both ear pinnae with $10 \mu \mathrm{g}$ whey or $1 \mu \mathrm{g}$ PE in $20 \mu \mathrm{l}$ PBS to determine the acute allergic skin response, anaphylactic shock symptom scores and body temperature levels. On day 70 and 84, i.g. challenges (using $50 \mathrm{mg}$ whey or $15 \mathrm{mg}$ PE in $500 \mu \mathrm{lBS}$ ) were performed to measure mucosal mast cell degranulation in blood samples collected after $30 \mathrm{~min}$. After intraperitoneal (i.p.) challenges on day 77 and 91 (using $100 \mu \mathrm{g}$ whey or $100 \mu \mathrm{g}$ PE in $200 \mu \mathrm{l} \mathrm{PBS}$ ) anaphylactic shock symptom scores and body temperature levels were measured. At day 92, mice were killed with cervical dislocation and blood and organs were collected.

\section{Acute allergic skin response, anaphylaxis symptom score and body temperature after challenge}

After AIT, on day 65, all mice were anesthetized using inhalation of isoflurane to measure ear thickness in duplicate prior to and $1 \mathrm{~h}$ after an i.d. injection with allergen in both ear pinnae. Basal ear thickness $(\mu \mathrm{m})$ was subtracted from the ear thickness $1 \mathrm{~h}$ post-challenge to determine ear swelling as a measure for the acute allergic skin response. Body temperature was measured 30 min after the i.d. challenge using a rectal thermometer and signs of anaphylaxis were scored according to the method described by $\mathrm{Li}$ et al. [25]. The anaphylaxisassociated drop in body temperature reaches a maximum at time point $30 \mathrm{~min}$ after i.d. challenge. In addition, body temperature was measured every $10 \mathrm{~min}$ after the i.p. challenge on day 77, using a rectal thermometer and anaphylaxis was scored at time point $40 \mathrm{~min}$ after challenge [25].

\section{Levels of $\mathrm{mMCP}-1$ and allergen-specific $\lg \mathrm{E}, \lg \mathrm{G} 1, \lg \mathrm{G} 2 \mathrm{a}$ in serum}

Blood samples were collected at nine specific time points during the animal experiment (day 35, 50, 63, 65, 70, $78,84,92)$ via cheek puncture and after centrifugation $(10,000 \mathrm{rpm}$ for $10 \mathrm{~min})$ sera were stored at $-20^{\circ} \mathrm{C}$ until further analysis.

Levels of whey-specific immunoglobulin (Ig) E, IgG1 and IgG2a were determined by means of ELISA as described previously [24]. Briefly, 96-wells high-binding plates (Costar 3590, Corning Incorporated, Corning, NY, USA) were coated overnight at $4{ }^{\circ} \mathrm{C}$ with $100 \mu \mathrm{l}(20 \mu \mathrm{g} /$ $\mathrm{ml}$ ) whey in coating buffer (carbonate-bicarbonate buffer, 0.05 M, pH 9.6; Sigma-Aldrich Chemicals, Zwijndrecht, The Netherlands). The plates were washed (PBS with $0.05 \%$ Tween20) and blocked for $1 \mathrm{~h}$ (RT) in ELISA buffer (50 mM TRIS, $137 \mathrm{mM} \mathrm{NaCl}, 2 \mathrm{mM}$ EDTA and 0.05\% Tween20) with $0.5 \%$ BSA. Serum samples were diluted and incubated on the plates for $2 \mathrm{~h}$ (RT). After washing, $100 \mu \mathrm{l}$ biotin-labeled rat anti-mouse IgE, IgG1 and IgG2a ( $1 \mu \mathrm{g} / \mathrm{ml}$; BD Biosciences, Alphen aan den Rijn, The Netherlands) was incubated for $1.5 \mathrm{~h}$ (RT). Subsequently, plates were washed and incubated with streptavidin poly horseradish peroxidase (Sanquin, Amsterdam, The Netherlands) for $1 \mathrm{~h}$ (RT). After washing, a color reaction was initiated by adding o-phenylendiamine (Sigma). The reaction was stopped using $4 \mathrm{M} \mathrm{H}_{2} \mathrm{SO}_{4}$ and optical density was measured with a Benchmark microplate reader (BioRad, Hercules, CA, USA) at $490 \mathrm{~nm}$.

PE-specific IgE, IgG1 and IgG2a levels in serum were detected by ELISA as previously described [23]. Briefly, for IgG1 and IgG2a, 96-wells high-binding plates (Costar 
3590, Corning Incorporated, Corning, NY, USA) were coated overnight at $4{ }^{\circ} \mathrm{C}$ with $10 \mu \mathrm{g} / \mathrm{ml}$ PE in PBS followed by blocking $1 \mathrm{~h}$ (RT) with 0.5\% BSA-ELISA buffer. Serum samples were diluted and incubated for $2 \mathrm{~h}$ (RT). For detection, AP-coupled anti-IgG1 and anti-IgG2a were added for $1 \mathrm{~h}$ (RT). Subsequently, $1 \mathrm{mg} / \mathrm{ml} \mathrm{p-nitro-}$ fenylphosphate in diethanolamine buffer was used for the color reaction, which was stopped with a 10\% EDTA solution and absorbance was measured at $405 \mathrm{~nm}$ using an Asys expert 96 plate reader (Biochrom, Cambourne, UK).

To measure PE-specific IgE, 96-wells high-binding plates (Costar 3590, Corning Incorporated, Corning, NY, USA) were coated overnight at $4{ }^{\circ} \mathrm{C}$ with $1 \mu \mathrm{g} / \mathrm{ml}$ rat antimouse IgE (BD Biosciences) followed by blocking for $1 \mathrm{~h}$ (RT) with $0.5 \%$ BSA-ELISA buffer. Serum samples were diluted and incubated for $2 \mathrm{~h}$ (RT). Subsequently, PE-DIG conjugate solution was added for $1 \mathrm{~h}$ (RT). The coupling of DIG to PE was performed according to the manufacturer's instructions. Briefly, the coupled proteins were separated on a Sephadex G-25 column and labeling efficiency was determined by means of spectrophotometry at $280 \mathrm{~nm}$. After incubation for $1 \mathrm{~h}$ (RT) with peroxidaseconjugated anti-DIG fragments, a tetramethylbenzidine substrate $(0.1 \mathrm{mg} / \mathrm{ml})$ solution was used and the color reaction was stopped with $2 \mathrm{M} \mathrm{H}_{2} \mathrm{SO}_{4}$. Absorbance was measured at $450 \mathrm{~nm}$. Concentrations of IgE, IgG1 and IgG2a were calculated in arbitrary units (AU) using a standard curve of pooled sera from alum-i.p. whey- or PE-sensitized mice.

Mucosal Mast Cell Protease-1 (mMCP-1) was determined by using a mMCP-1 Sandwich ELISA kit (Mouse MCPT-1 Ready-SET-Go! ${ }^{\circledR}$ ELISA, eBioscience, Breda, The Netherlands) according to the manufacturer's instructions. Levels of mMCP-1 were determined in serum samples obtained $30 \mathrm{~min}$ after i.g. challenge.

\section{Analysis of T cell populations using flow cytometry}

After collection and homogenization of the spleen (incl. red blood cell lysis) and the mesenteric lymph nodes (MLN; only in the CMA model), single cell suspensions were used to analyze $\mathrm{T}$ cell subsets by flow cytometry. $5-10 \times 10^{5}$ cells per well were collected in fluorescence activated cell sorting (FACS) buffer (PBS containing $0.25 \% \mathrm{BSA}, 0.05 \% \mathrm{NaN}_{3}$ and $0.5 \mathrm{mM}$ EDTA) and plated. The cells were blocked for 20 min using PBS containing $1 \% \mathrm{BSA}$ and $5 \%$ fetal calf serum (FCS) in the CMA experiment and Fc block (anti-mouse CD16/32 clone 93, eBioscience) in the PNA experiment. Subsequently, cells were stained with the following antibodies in FACS buffer for $30 \mathrm{~min}$ at $4{ }^{\circ} \mathrm{C}$ : anti-CD4-PerCpCy5.5 (1:100, clone RM45), anti-CD25-AlexaFluor 488 (1:100, clone PC61.5), anti-FoxP3-APC (1:50, clone FJK-16s), anti-CD69-APC
(1:100, clone H1.2F3), anti-CXCR3-PE (1:50, clone CXCR3-173), anti-CD3e-PerCpCy5.5 (1:100, clone 145$2 \mathrm{C} 11)$, anti-CD8 $\alpha$-PE (1:100, clone 53-6.7), anti-CD4FITC (1:200, clone RM4-5), anti-CD25-PE (1:200, clone PC61.5), anti-CD3e-FITC (1:200, clone 145-2C11) from eBioscience, anti-T1/ST2-FITC (1:50, clone DJ8) from mdbioproducts, anti-CD4-FITC (1:100, clone RM45), anti-CD4-PerCp (1:200, clone RM4-5), anti-CD8 $\alpha$ PerCp (1:100, clone 53-6.7), anti-CD4-APC (1:200, clone RM4-5), anti-CD69-PE (1:200, clone H1.2F3) from BD Biosciences. Antibody concentrations were individually titrated beforehand and isotype controls were used. Dead and/or aggregated cells were excluded based on forward/ sideward scatter properties. Cut-off gates for positivity were established using the fluorescence-minus-one (FMO) technique. Cells stained for extracellular markers were fixed using $1 \%$ paraformaldehyde and cells stained for intracellular FoxP3-APC were permeabilized and fixed using the buffer set purchased from eBioscience according to the manufacturer's protocol. Analysis of the CMA samples was performed on the FACS Canto II (BD Biosciences) and Flowlogic software (Inivai Technologies, Mentone, Australia). Analysis of the PNA samples was performed on the BD Accuri ${ }^{\mathrm{TM}} \mathrm{C} 6$ flow cytometer and BD sampler software (BD Biosciences).

\section{Cytokine release after ex vivo stimulation with whey or PE} $8 \times 10^{5}$ cells per well in $200 \mu$ derived from spleen and MLN (in CMA model) were cultured in U-bottom culture plates (Greiner, Frickenhausen, Germany) using RPMI 1640 medium (Lonza, Verviers, Belgium) with $10 \%$ FCS, penicillin $(100 \mathrm{U} / \mathrm{ml}) /$ streptomycin $(100 \mu \mathrm{g} / \mathrm{ml})$ (Sigma) and $\beta$-mercaptoethanol (CMA model, $20 \mu \mathrm{M}$ ). All cells received either stimulation with culture medium as a negative control, a polyclonal stimulation with antiCD3 (CMA model; $1 \mu \mathrm{g} / \mathrm{ml}$, clone 17A2, eBioscience) or anti-CD3/CD28 (PNA model; $1 \mu \mathrm{g} / \mathrm{ml}$, clone 145-2C11 and clone 37.51, eBioscience) or antigen-specific stimulation with whey $(50 \mu \mathrm{g} / \mathrm{ml})$ or PE $(100 \mu \mathrm{g} / \mathrm{ml})$. Plates were incubated for $48 \mathrm{~h}$ (anti-CD3 or anti-CD3/CD28) or $96 \mathrm{~h}$ (whey or PE) to assess production of interleukin (IL)-5, IL-10, IL-13 and Interferon $\gamma$ (IFNY) by T cells. Culture supernatants were collected and stored at $-20{ }^{\circ} \mathrm{C}$ until further analysis with the Ready-SET-Go! ${ }^{\circledR}$ ELISA (eBioscience) according to the manufacturer's instructions.

\section{Statistics}

The acute allergic skin response, body temperature levels, flow cytometry data, cytokine concentrations and serum mMCP-1 and immunoglobulin levels are depicted as mean \pm SEM and were statistically analyzed with GraphPad Prism software version 6.00 (GraphPad software, La Jolla, CA, USA) using one-way ANOVA and Dunnett's 
post hoc test for multiple comparisons to compare the treatment groups with the sensitized control animals within each individual experiment. Body temperature curves were statistically analyzed using a repeated measures two-way ANOVA and Dunnett's post hoc test for multiple comparisons with matched values. Anaphylaxis symptom scores were analyzed using Kruskal-Wallis test for nonparametric data with Dunn's post hoc test. Results were considered statistically significant when $\mathrm{P}<0.05$.

\section{Results}

Reduction in allergic manifestations upon challenge with whey or PE in OIT and SCIT mice

The acute allergic skin response, measured as ear swelling after i.d. injection with whey or PE, was increased in sensitized mice (whey/PE no IT) compared to sham-sensitized mice (PBS no IT) (Fig. 2a, b). In the CMA model, SCIT reduced the acute allergic skin response only at a dose of $10 \mu \mathrm{g}$, whereas OIT reduced acute allergic skin responses at all dosages (Fig. 2a). Furthermore, both SCIT $(10,25 \mu \mathrm{g})$ and $\operatorname{OIT}(1,10,100 \mathrm{mg})$ reduced anaphylactic shock symptom scores (Fig. 2c). SCIT and OIT prevented the characteristic drop in body temperature observed during anaphylaxis and this effect appeared to be doserelated (Fig. 2d). In the PNA model, SCIT $(100 \mu \mathrm{g})$ and $\operatorname{OIT}(0.15,15 \mathrm{mg})$ reduced the acute allergic skin response (Fig. 2b). No anaphylactic response was induced after i.d. administration of the used PE dosage, therefore no body temperature and anaphylactic shock symptom score data were included. The i.p. challenge performed in PE-sensitized mice on day 77 indicated protection against clinical responses in a dose-related manner after both SCIT and OIT. Both the drop in body temperature (Fig. 2g, h) and the anaphylactic shock symptom scores (Fig. 2i) were significantly reduced in all AIT groups. The i.p. challenge performed in the whey-sensitized mice on day 77 did not show protection against clinical signs, since the used dose of $100 \mu \mathrm{g}$ induced severe anaphylaxis in all groups (data not shown). In addition, a second i.p. challenge performed on day 91 in both food allergy models did not induce an anaphylactic response in allergensensitized control animals (data not shown).

To determine the effect of OIT and SCIT on the local effector response in the gastrointestinal tract, mMCP-1 concentrations were measured in serum collected $30 \mathrm{~min}$ after i.g. challenge (day 70) (Fig. 2e, f). Mast cell degranulation was reduced in all treatment groups in the CMA model, except OIT with $0.1 \mathrm{mg}$ whey (Fig. 2e). A second i.g. challenge (day 84) did not induce detectable mMCP-1 levels in serum (data not shown). In PE-sensitized animals, a reduction in mMCP-1 was observed in all SCIT groups and the 0.15 and $1.5 \mathrm{mg}$ OIT groups (Fig. 2f). The second i.g. challenge (day 84) showed a similar induction of mMCP-1 in sensitized animals and this increase was absent in SCIT $(100 \mu \mathrm{g})$ and OIT $(0.15,15 \mathrm{mg}$, data not shown). In short, SCIT and OIT induced clinical protection against food challenges in both the CMA and PNA model.

\section{Induction of allergen-specific IgE upon challenge absent in OIT and SCIT mice}

Allergen-specific IgE, IgG1 and IgG2a levels in serum were measured in particular to investigate whether OIT and SCIT modulated the humoral response. During and after AIT (day 50, 63), SCIT increased allergen-specific IgE levels in the PNA model (Fig. $3 \mathrm{~b}$ ) and in the CMA model with a dose of $25 \mu \mathrm{g}$ (Fig. 3a). At day 70, 5 days after the i.d. challenge, the rise in allergen-specific IgE observed in sensitized control animals compared to sham-sensitized control animals was absent in the OIT and SCIT mice (Fig. 3a-d). In addition, OIT with $100 \mathrm{mg}$ whey showed significantly lower whey-specific IgE levels compared to the whey-sensitized control group (Fig. 3c). High dose SCIT and OIT induced IgG1 and IgG2a in the CMA and PNA model (day 63, Fig. 3e-l). The induction of allergen-specific IgG1 and IgG2a was delayed in sensitized control mice; an increase was observed after the i.d. challenge (day 70) and levels appeared to continuously rise upon repeated challenges (day 70, 78, 84 and 92). However, allergen-specific IgG1 levels in the SCIT and OIT mice did not further increase after day 70/78 (Fig. 3e-h) despite the challenges. In summary, the data demonstrate that for both allergens OIT and SCIT protected against a challenge-induced rise in allergen-specific IgE and induced allergen-specific IgG1 and IgG2a during immunotherapy.

\section{Shifted T cell profile in lymph organs after OIT and SCIT}

In the spleen, the percentage of activated Th2 cells (T1/ ST2+ CD69+ of CD4+ cells) was elevated in wheysensitized control animals compared to sham-sensitized control animals (Fig. 4a). OIT (all dosages) and SCIT (10, $25 \mu \mathrm{g}$ ) reduced the percentage of activated Th2 cells. This reduction coincided with an increase in the percentage of activated Th1 cells (CXCR3+ CD69+ of CD4+ cells) in the $25 \mu \mathrm{g}$ SCIT and $10 \mathrm{mg}$ and $100 \mathrm{mg}$ OIT groups (Fig. 4c) compared to the whey-sensitized control animals. In contrast to the CMA model, no difference in the percentage of activated Th2 cells was observed in PEsensitized control animals compared to sham-sensitized control animals (Fig. 4b). The percentage of activated Th1 cells was decreased in PE-sensitized mice compared to sham-sensitized mice (Fig. 4d). In addition, SCIT and OIT with PE $(15 \mathrm{mg})$ increased the percentage of activated CD4+ T cells (CD4+ CD69+ of CD3+ cells) compared to the PE-sensitized control animals (Fig. 4f). 

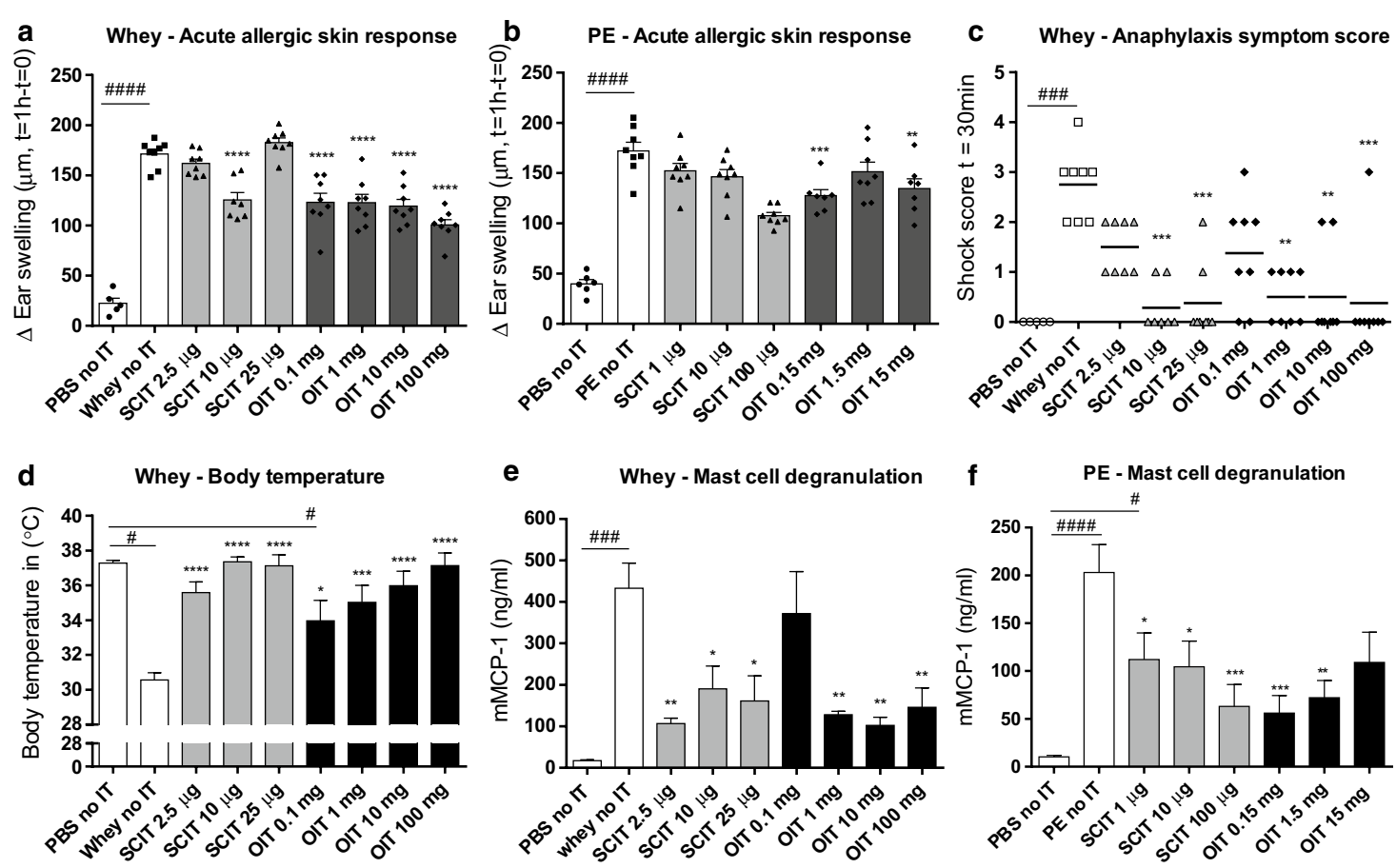

g

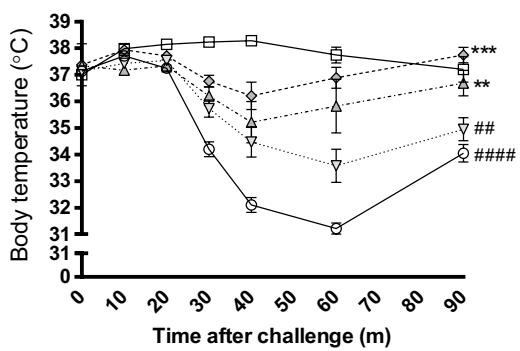

i

PE - Anaphylaxis symptom score h PE - Body temperature

$\square$ PBS noIT - PE no IT $\nabla$ SCIT $1 \mu \mathrm{g}$ $\Delta$ SCIT $10 \mu \mathrm{g}$ $\diamond$ SCIT $100 \mu \mathrm{g}$
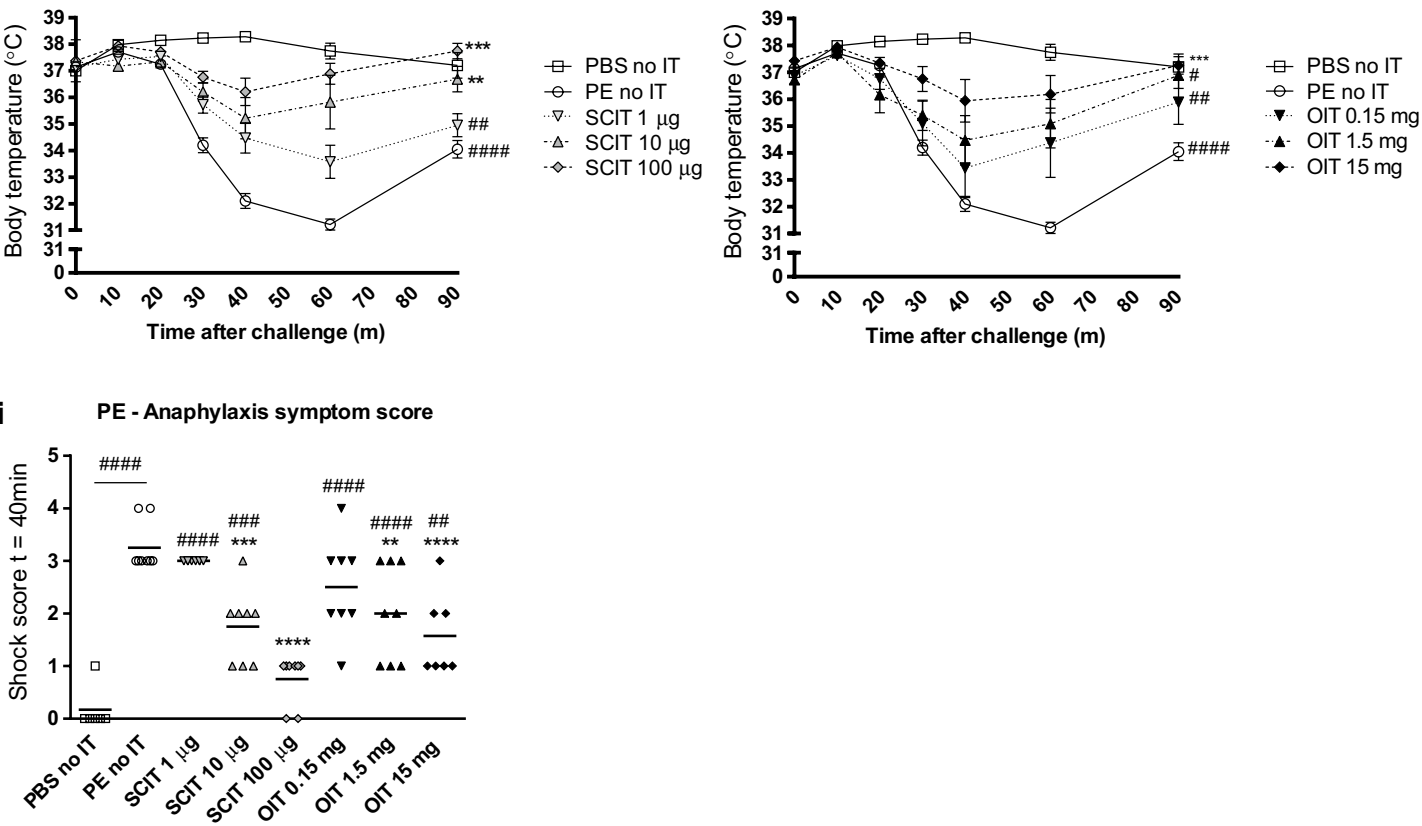

Fig. 2 Allergic manifestations evaluated in whey- or PE-sensitized mice after receiving SCIT and OIT. a, b Acute allergic skin response measured as $\triangle$ ear swelling $1 \mathrm{~h}$ after i.d. challenge. c Anaphylactic shock symptom scores determined 30 min after i.d. challenge in CMA model. d Body temperature measured 30 min after i.d. challenge in CMA model. e, f Concentrations of mMCP-1 in serum collected 30 min after i.g. challenge. $\mathbf{g}$, h Change in body temperature after i.p. challenge in PNA model. i Anaphylactic shock symptom scores determined 40 min after i.p. challenge in PNA model. Data are represented as mean \pm SEM $n=6-8$ mice/group. Statistical analysis was performed using one-way ANOVA and Dunnett's post hoc test for multiple comparisons or a repeated measures two-way ANOVA and Dunnett's post hoc test for multiple comparisons with matched values for the temperature curve in $\mathrm{g}-\mathrm{h}$. ${ }^{\#} \mathrm{P}<0.05$; ${ }^{\# \#} \mathrm{P}<0.01$; ${ }^{\# \#} \mathrm{P}<0.001$; ${ }^{\# \# \#} \mathrm{P}<0.0001$ compared to sham control. ${ }^{*} \mathrm{P}<0.05$; ${ }^{* *} \mathrm{P}<0.01 ;{ }^{* * *} \mathrm{P}<0.001$; ***P $<0.0001$ compared to whey- or PE-sensitized control. OIT oral immunotherapy, SCIT subcutaneous immunotherapy, PE peanut extract; CT cholera toxin, $m M C P-1$ mucosal mast cell protease-1, IT immunotherapy 

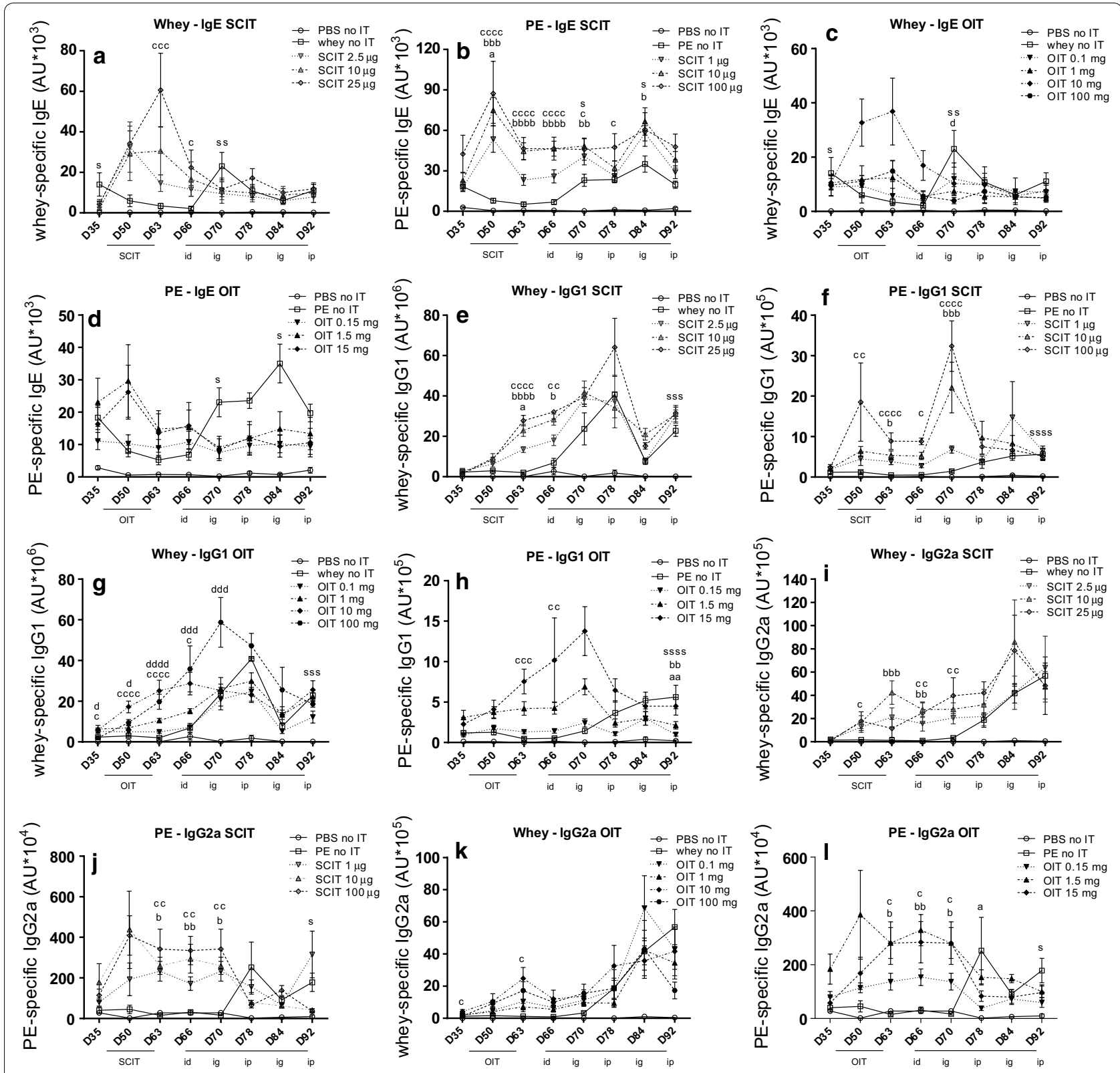

Fig. 3 Allergen-specific lgE, lgG1 and IgG2a levels in serum determined by ELISA. a, b Allergen-specific lgE in SCIT groups. c, d Allergen-specific IgE in OIT groups. e, f Allergen-specific lgG1 in SCIT groups. $\mathbf{g}$, h Allergen-specific lgG1 in OIT groups. $\mathbf{i}$, j Allergen-specific lgG2a in SCIT groups. k, I Allergen-specific IgG2a in OIT groups. Data are represented as mean \pm SEM $n=6-8$ mice/group. Statistical analysis was performed on each individual time point using one-way ANOVA and Dunnett's post hoc test for multiple comparisons. All treatment groups were compared to the sensitized control group and significant differences were indicated with letters e.g. ${ }^{a} \mathrm{P}<0.05$; ${ }^{\text {aap }}<0.01$; ${ }^{\text {aaa }} \mathrm{P}<0.001$; ${ }^{\text {aaaa }} \mathrm{p}<0.0001$. In CMA figures: a for SCIT $2.5 \mu \mathrm{g}$ and OIT $0.1 \mathrm{mg}$, b for SCIT $10 \mu \mathrm{g}$ and OIT $1 \mathrm{mg}$, c for SCIT $25 \mu \mathrm{g}$ and OIT $10 \mathrm{mg}$, d for OIT $100 \mathrm{mg}$ and s for sham control. In PNA figures: a for SCIT $1 \mu \mathrm{g}$ and OIT $0.15 \mathrm{mg}$, b for SCIT $10 \mu \mathrm{g}$ and OIT $1.5 \mathrm{mg}$ and c for SCIT $100 \mu \mathrm{g}$ and OIT $15 \mathrm{mg}$ and s for sham control. OIT oral immunotherapy, SCIT subcutaneous immunotherapy, IT immunotherapy, PE peanut extract, id intradermal challenge, ig intragastric challenge, ip intraperitoneal challenge

In the MLN collected in the CMA model, the percentage of CD4+ CD25+ FoxP3+ Tregs was elevated in OIT mice $(1,10 \mathrm{mg})$ (Fig. 4i) compared to whey-sensitized control animals. In addition, an increase in percentage of activated Th2 cells in the $10 \mathrm{mg}$ OIT group was observed.
No effect of OIT and SCIT on the induction of Tregs was found in spleen in either the CMA or the PNA model (Fig. 4g, h). Briefly, we observed differences in the percentages of $\mathrm{T}$ cells in the lymph organs of the cow's milk and peanut allergic mice in response to therapy. 


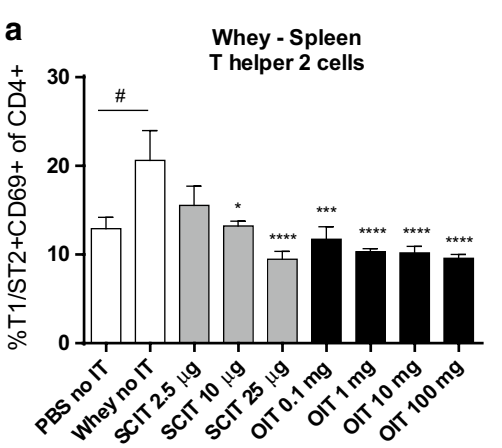

d
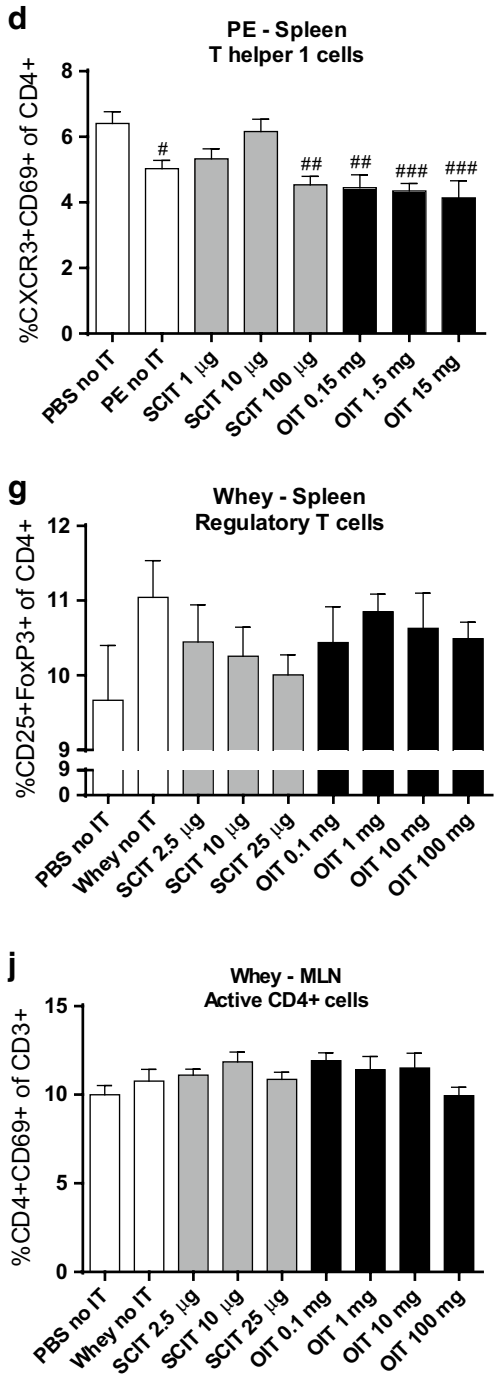

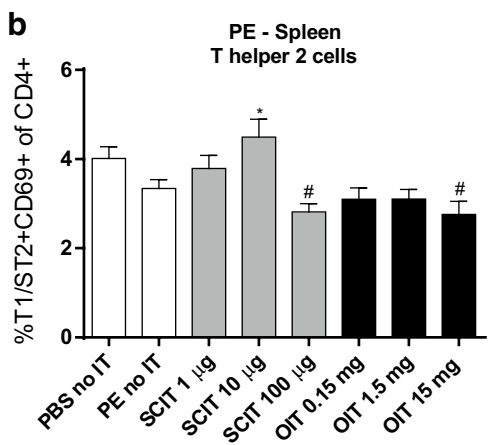

e

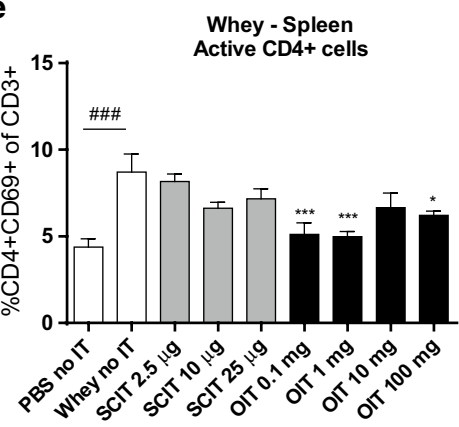

h
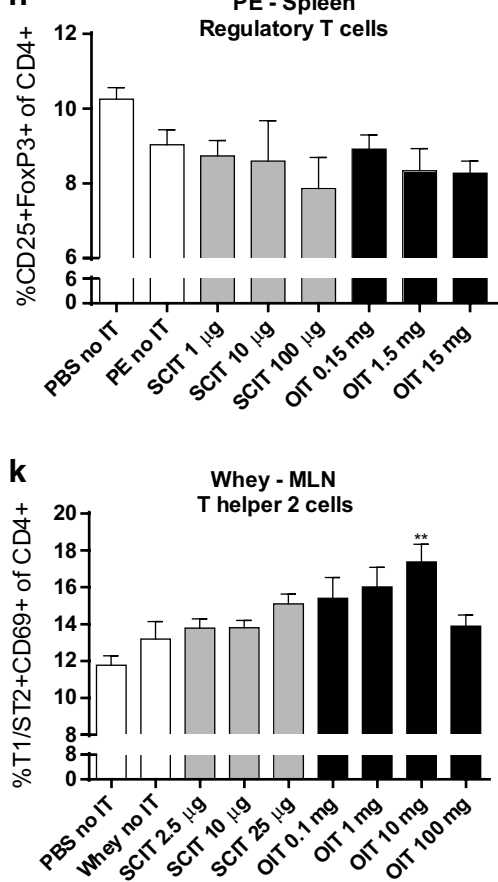

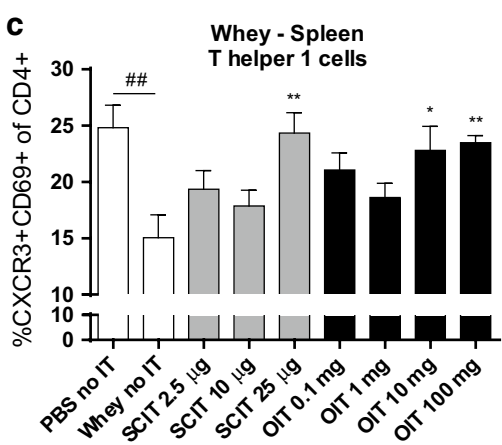

f
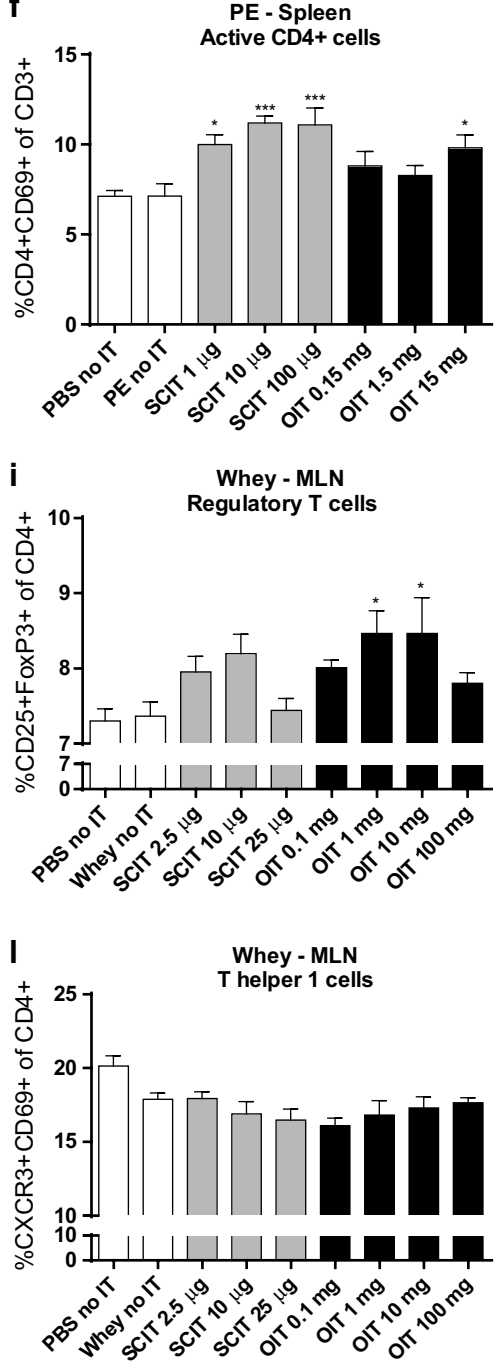

Fig. 4 Flow cytometric analysis of T cell populations in the spleen and MLN. Cells were gated based on FSC-SSC properties and the Fluorescenceminus-one (FMO) technique. $\mathbf{a}, \mathbf{b}$ Percentage of activated Th2 cells (T1/ST2+ CD69+ of CD4+) in spleen. $\mathbf{c}$, d Percentage of activated Th1 cells (CXCR3+ CD69+ of CD4+) in spleen. e, f Percentage of activated CD4+ cells (CD4+ CD69+ of CD3+) in spleen. $\mathbf{g}$, $\mathbf{h}$ Percentage of Tregs (CD25+ FoxP3+ of CD4+) in spleen. i Percentage of Tregs (CD25+ FoxP3+ of CD4+) in MLN of CMA animals. $\mathbf{j}$ Percentage of activated CD4+ cells (CD4+ CD69+ of CD3+) in MLN of CMA animals. k Percentage of activated Th2 cells (T1/ST2+ CD69+ of CD4+) in MLN of CMA animals. I Percentage of activated Th1 cells (CXCR3+ CD69+ of CD4+) in MLN of CMA animals. All data are represented as mean \pm SEM $n=6 / 8$ mice/group. Statistical anal-

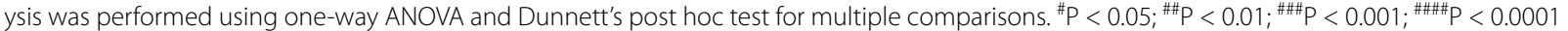
compared to sham control control. ${ }^{*} \mathrm{P}<0.05 ;{ }^{* * P}<0.01 ;{ }^{* *} \mathrm{P}<0.001 ;{ }^{* * *} \mathrm{P}<0.0001$ compared to whey- or PE-sensitized control. PE, peanut extract; OIT, oral immunotherapy; SCIT, subcutaneous immunotherapy; IT, immunotherapy 


\section{Altered cytokine production after ex vivo stimulation of lymphocytes with whey or PE}

Cellular activation was confirmed in the control conditions of the ex vivo stimulation assay; a significant increase in IL-5, IL-10, IL-13 and IFN $\gamma$ production was observed in all groups after polyclonal stimulation of cultured cells using anti-CD3 (CMA model) or anti-CD3/ CD28 (PNA model) compared to stimulation with only medium in both food allergy models (data not shown). Ex vivo stimulation with whey increased the IL-5, IL-10 and IL-13 concentration in supernatants of splenocyte cultures derived from whey-sensitized control animals (Fig. 5a, c, e). OIT (1, 10 and $100 \mathrm{mg}$ ) reduced the release of IL-5 and IL-13. Except for $100 \mathrm{mg}$ OIT, IL-10 levels remained high in the OIT groups. SCIT did not change cytokine levels. The Th1-related IFNy release upon stimulation did not differ among the groups (Fig. $5 \mathrm{~g}$ ). In the PNA model, cytokine production was affected by SCIT but not by OIT (Fig. 5b, d, f, h). Compared to PE-sensitized control mice, SCIT increased antigen-induced release of IL-5 at 1 and $10 \mu \mathrm{g}$ (Fig. 5b) and IL-10 at 10 and $100 \mu \mathrm{g}$ (Fig. 5d). No change in IL-13 production was observed in the SCIT groups (Fig. 5f). Again, IFNy release upon stimulation did not differ between groups (Fig. 5h). Overall, SCIT induced an increase (IL-5, IL-10) in the PNA model, whereas SCIT in the CMA model did not affect cytokine levels. OIT did not affect cytokine production in the PNA model, whereas it reduced Th2associated cytokine production in the CMA model.

\section{Discussion}

We aimed to compare the efficacy of OIT and SCIT in models of PNA and CMA and to determine the dose of allergen needed to effectively modify parameters of allergy. We have shown in both models that OIT and SCIT reduced clinical manifestations of food allergy and resulted in comparable changes in serum levels of allergen-specific IgE and IgG subtypes. Differences in T cell populations and cytokine profiles suggest a potential difference in the mechanism of AIT for PNA and CMA.

While both types of immunotherapy were able to decrease allergic manifestations upon challenge, the effective therapeutic dose differed per allergen. OIT using $0.1 \mathrm{mg}$ whey did not decrease signs of anaphylaxis and only mildly prevented the drop in body temperature. The efficacy of OIT was evident in the groups receiving $1 \mathrm{mg}$ whey or higher. In SCIT, $10 \mu \mathrm{g}$ whey was the most effective dose. In the PNA model, the intermediate and high dosages $(1.5,15 \mathrm{mg}$ OIT and 10, $100 \mu \mathrm{g}$ SCIT) were the most effective in modulation of disease parameters.

To investigate the effect of OIT and SCIT on mucosal mast cell degranulation, all mice were challenged per oral gavage. Although OIT with $0.1 \mathrm{mg}$ whey was ineffective,
SCIT and OIT effectively reduced mMCP-1 levels in both food allergy models. This finding indicates that regular administration of an allergen dose above a certain threshold influences responsiveness of effector cells along the gastrointestinal tract. This is a known effect of AIT and reflects desensitization. Repeated stimulation of the FceRI present on basophils during OIT in peanut allergic individuals reduces basophil activation as shown by down-regulation of the activation marker CD63 [26]. Another possible explanation for the reduced release of mediators by effector cells might be a reduced number of basophils and mast cells in the early phase of immunotherapy [19]. In addition, repeated exposure to the allergen can contribute to exhaustion of effector cells [27]. In the CMA model, a second i.g. challenge after 2 weeks resulted in a low mMCP-1 concentration in the serum of the whey-sensitized control group. This observation might be associated with the low levels of allergen-specific IgE in serum of the whey-sensitized control animals on day 84, while whey-specific IgG2a levels were increased. Such low IgE levels may be insufficient to re-sensitize mucosal mast cells [28]. In vitro studies showed that mast cells are able to refill their granules and respond again to an allergen challenge after 24-48 h [29]. In accordance, PE-specific IgE levels in serum of the sensitized control animals were not decreased and IgG2a levels were not elevated at day 84 and similar mMCP-1 levels were found upon a second i.g. challenge when compared to the first i.g. challenge. Although protection against i.p. challenge-induced anaphylaxis was shown in OIT and SCIT mice in the PNA model (day 77), a second i.p. challenge did not induce anaphylaxis in allergen-sensitized animals (both CMA and PNA model, day 91). We hypothesized that repeated systemic (i.p.) challenges, as conducted in the current models to ensure a detectable Th2 cell-mediated effector response, leads to exhaustion of the effector cells present in the peritoneum and this unintentionally affects allergic outcomes.

In humans, AIT is known to increase antigen-specific $\mathrm{IgE}$ in serum. However, if the treatment is prolonged for a period of months or even years, IgE levels tend to decline [30]. Peanut allergic individuals subjected to OIT showed an initial increase in IgE, but levels were stabilized despite an oral food challenge [31]. In accordance, our findings indicate an increase in allergen-specific IgE in mice receiving OIT and SCIT, followed by a return to baseline when immunotherapy was discontinued. Remarkably, IgE levels failed to increase after the allergen challenges in the SCIT and OIT groups. The induction of allergen-specific IgG1 and IgG2a by OIT and SCIT appeared to be dose-dependent. In humans, IgG4 levels are elevated during immunotherapy and are associated with protection against clinical symptoms [31, 32]. IgG 

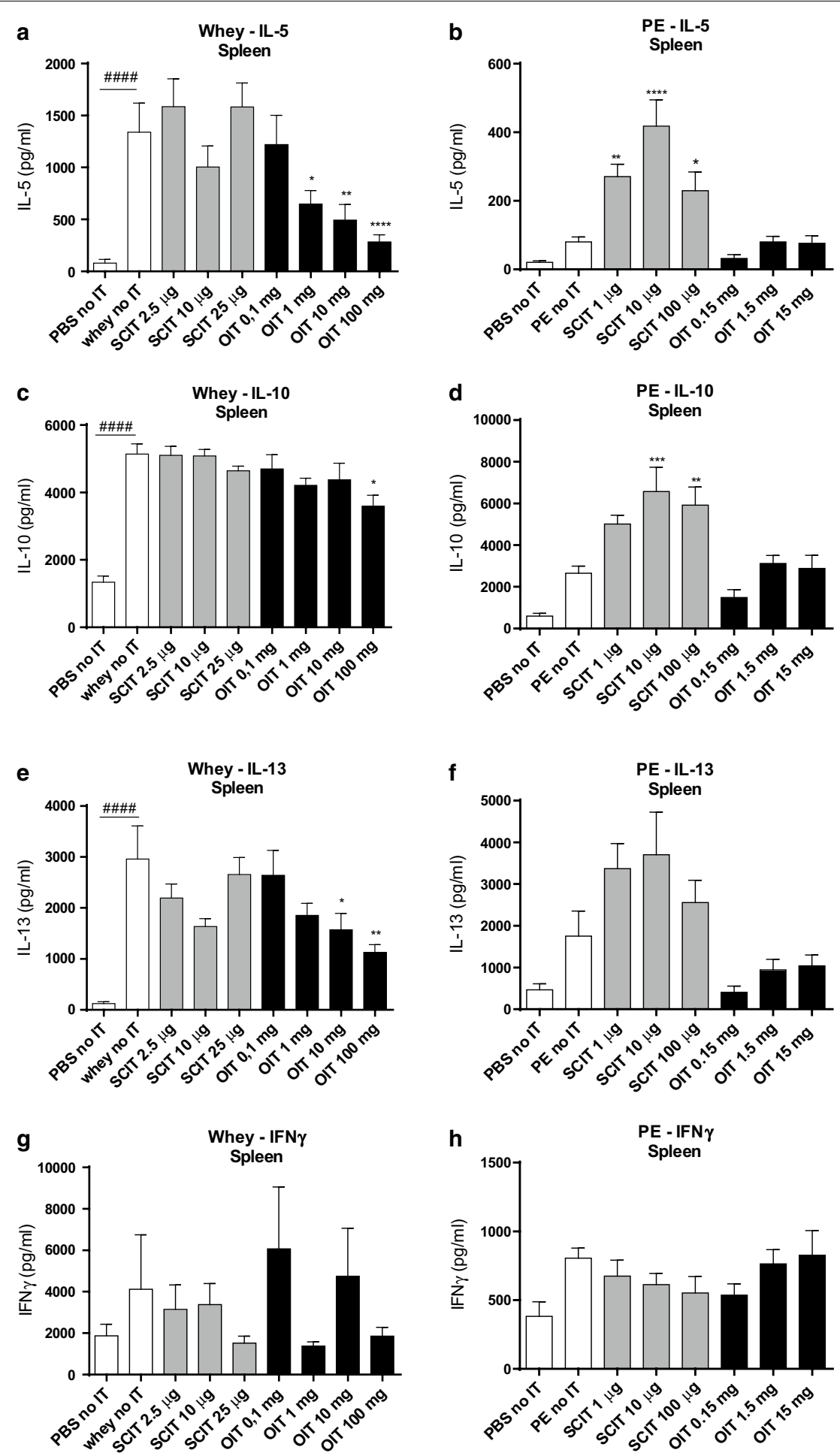

Fig. 5 Cytokine concentrations after ex vivo stimulation of splenocytes with whey or PE determined by ELISA. Splenocytes were cultured for $96 \mathrm{~h}$ in the presence of $\mathrm{PE}$, whey or medium (medium data not shown). $\mathbf{a}, \mathbf{b} \mathrm{IL}-5$ concentration. $\mathbf{c}, \mathbf{d} \| \mathrm{L}-10$ concentration. $\mathbf{e}, \mathbf{f} \mathrm{LL}-13$ concentration. $\mathbf{g}, \mathbf{h} \mathrm{IFNy}$ concentration. Data are represented as mean \pm SEM $n=6 / 8$ mice/group. Statistical analysis was performed using one-way ANOVA and Dunnett's

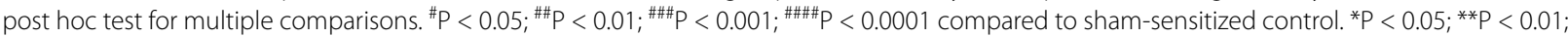
${ }^{* * *} \mathrm{P}<0.001 ;{ }^{* * *} \mathrm{P}<0.0001$ compared to whey- or PE-sensitized control. PE peanut extract, OIT oral immunotherapy, SCIT subcutaneous immunotherapy, IT immunotherapy 
subtypes are proposed to capture the antigen and thereby inhibit binding to IgE present on mast cells and basophils and thus prevent degranulation [19]. The reduced mMCP-1 release measured after i.g. challenge might be explained by the elevated IgG subtype levels in serum. Furthermore, IgG levels were increased by the challenge protocol, including in the serum of the allergen-sensitized control animals. This finding might explain the absence of clinical signs in the follow-up challenges in the CMA model.

The effect of OIT and SCIT on the humoral response can be linked to the percentages of $\mathrm{T}$ helper cell subsets in the lymphoid organs in the CMA model, but not in the PNA model. Specific IgE production by plasma cells is sustained by a Th2 cell dominated immune response in the presence of IL-4, IL-5 and IL-13 [33]. Clinical protection after OIT in peanut allergic subjects in a randomized controlled study was accompanied by a reduction in IL- 5 and IL-13 concentrations [31]. Skewing of the immune response from a Th2 profile towards a more regulatory profile is associated with a modified cytokine milieu [34]. The reduced percentage of activated Th2 cells in the spleen of OIT mice (CMA model) was accompanied by a dose-dependent reduction in the IL-5 and IL-13 concentration in stimulated cultures. This observation is consistent with the fact that exposure to a high allergen dose leads to anergy in specific T-cells [35]. On the contrary, IL-5 and IL-13 production was not decreased in the SCIT groups, although the percentage of activated Th2 cells was decreased in the 10 and $25 \mu \mathrm{g}$ groups. These findings suggest that the route of antigen administration is important in the modulation of specific $\mathrm{T}$ cell responsiveness during immunotherapy. Th2-associated cytokine IL-4 was not detected in the stimulated cell cultures, as was previously described for the current food allergy model with the $\mathrm{C} 3 \mathrm{H} / \mathrm{HeOuJ}$ strain [36]. A similar pattern of IL-5 and IL-13 levels as described for spleen was observed in MLN culture supernatants in the CMA model, indicating a suppressed Th2 responsiveness after OIT but not after SCIT. Nevertheless, a tendency towards an increase in activated Th2 cells was observed in the MLN of the OIT groups, with a significant difference in the OIT $10 \mathrm{mg}$ group. In the PNA model, SCIT increased levels of IL-5 and IL-10 compared to the PE-sensitized control animals, whereas OIT did not have an effect on cytokine production. Earlier studies show that tolerance induction by SCIT is accompanied by a shift from a Th2 cytokine profile towards a Th1 cytokine profile, but there are discrepancies in the literature [37]. The observed differences in Th2 cytokine production between OIT and SCIT and between the CMA and PNA models might be explained by the induction of antigen-specific Tregs that can exert a suppressive function towards effector T cells $[38,39]$.
High dose SCIT and OIT induced a shift in the percentages of activated splenic Th1 and Th2 cells after the final i.p. challenge in the CMA model but not in the PNA model. The observation in the CMA model is in accordance with the hypothesis that oral tolerance induction is characterized by a shift from a Th2 response towards a Th1 response [33]. Furthermore, low-dose induction of tolerance is accompanied by increased numbers of CD4+ CD25+ FoxP3+ Tregs [33]. Indeed, this was observed in the CMA model where OIT $(1,10 \mathrm{mg})$ increased the percentage of CD4+ CD25+ FoxP3+ Tregs in the MLN. The fact that no difference in percentage of FoxP3+ Tregs was observed in spleen (PNA and CMA), is contradictory to the results published by Dioszeghy et al. [17], who have shown an increase in FoxP3+ Tregs in the spleen of peanut-allergic mice subjected to OIT. This dissimilarity might be explained by the different mouse strains used in both studies; $\mathrm{C} 3 \mathrm{H} / \mathrm{HeOuJ}$ and $\mathrm{BALB} / \mathrm{c}$ show differences in allergic responses [36]. In addition, we could not link splenic ex vivo IL-10 levels to the presence of Tregs in both food allergy models. An increase in the IL-10 concentration was found in allergen-stimulated cultures derived from lymph organs of allergic mice, indicating the contribution of Th2-derived IL-10 [40, 41]. Hence, clinical protection observed after AIT and allergen challenge in both the CMA and PNA models might partially be explained by the induced IgG1 and IgG2a levels in combination with low IgE levels. Given the fact that IgG can also drive an alternative food-induced anaphylaxis pathway [42], the potential protective effect of IgG1 and IgG2a needs to be confirmed with a more mechanistic approach.

Despite differences between the CMA and PNA models, overall, the reported clinical, cellular and humoral data can be linked to our current understanding of oral tolerance and immunotherapy mechanisms in humans [19]. However, future use of both models would require further investigation of the exact role of immunoregulatory mechanisms, such as regulatory $\mathrm{T}$ cells or antibodymediated protection, and of long term effects of the therapeutic strategies.

\section{Conclusion}

In conclusion, the murine CMA and PNA studies showed that clinical protection can be achieved via OIT and SCIT. Although similar allergen-specific immunoglobulin patterns were observed, differences in $\mathrm{T}$ cell populations and cytokine responses were shown. More insight into the mechanism of (long term) tolerance induction is needed, nonetheless, our findings contribute to the development of effective AIT protocols. In the future, the current OIT models will be used to study the possible benefit of using immunomodulatory food components 
(e.g. non-digestible oligosaccharides) as adjunct therapy to support antigen-specific immunotherapy in terms of efficacy and safety.

\begin{abstract}
Abbreviations
AIT: antigen-specific immunotherapy; CMA: cow's milk allergy; PNA: peanut allergy; OIT: oral immunotherapy; SCIT: subcutaneous immunotherapy; FoxP3: forkhead box protein 3; i.g.: intragastric; PE: peanut extract; CT: cholera toxin; i.d.: intradermal; i.p.: intraperitoneal; Ig: immunoglobulin; Th: T helper; IL: interleukin; DBPCFC: double-blind placebo-controlled food challenge; Treg: regulatory $T$ cell; mMCP-1: murine mast cell protease-1; IFNy: Interferon $\gamma$; MLN: mesenteric lymph nodes; IT: immunotherapy.
\end{abstract}

\section{Author details}

${ }^{1}$ Department of Pharmacology, Faculty of Science, Utrecht Institute for Pharmaceutical Sciences, Utrecht University, Utrecht, The Netherlands. ${ }^{2}$ Immunology Platform, Nutricia Research, Utrecht, The Netherlands. ${ }^{3}$ Department of Immunotoxicology, Faculty of Veterinary Medicine, Institute for Risk Assessment Sciences, Utrecht University, PO Box 80177, 3508 TD Utrecht, The Netherlands. ${ }^{4}$ Present Address: Yalelaan 104, 3594 CM Utrecht, The Netherlands.

\section{Authors' contributions}

MMV and LW performed the literature search, data collection, analysis and interpretation, created the figures and wrote the manuscript. JJS and BCAMvE. designed the experimental set-up and JJS wrote the animal applications. JJS, BCAMvE, LMJK, RHHP, LEMW and JG contributed to analysis and interpretation of data and manuscript writing.

\section{Acknowledgements}

The authors would like to thank M. van Roest, L. Kruijssen, M.W.H.C. BolSchoenmakers, M.A.P. Diks, G.M. Dingjan and G.A. Hofman for their technical assistance. All authors are part of the NUTRALL research consortium. This work is supported by a grant from STW, project number 12652 .

\section{Competing interests}

LM.J.K., B.C.A.M.v.E. and J.G. are partly employed by Nutricia Research, Utrecht, The Netherlands.

\section{Animal ethics approval}

All animal procedures were approved by the Ethical Committee of Animal Research of Utrecht University, Utrecht, The Netherlands (registered by DEC2014.III.03.032, studies 104820-1 and 104820-2).

\section{Availability of data and materials}

The datasets used and/or analyzed during the current studies are available from the corresponding author on reasonable request.

\section{Consent for publication}

Not applicable.

\section{Funding}

This research was financially supported by the STW 'Open Technology Program' grant and embedded in the NUTRALL consortium project entitled: "Nutrition-based approach to support antigen-specific immunotherapy for food allergies".

\section{Publisher's Note}

Springer Nature remains neutral with regard to jurisdictional claims in published maps and institutional affiliations.

Received: 25 November 2016 Accepted: 14 September 2017 Published online: 29 September 2017

\section{References}

1. Prescott SL, et al. A global survey of changing patterns of food allergy burden in children. World Allergy Organ J. 2013;6(1):21.
2. Sampson HA. Update on food allergy. J Allergy Clin Immunol. 2004;113(5):805-19 (quiz 820)

3. Ludman S, Shah N, Fox AT. Managing cows' milk allergy in children. BMJ. 2013;347:f5424

4. Al-Ahmed N, Alsowaidi S, Vadas P. Peanut allergy: an overview. Allergy Asthma Clin Immunol. 2008;4(4):139-43.

5. Erekosima $\mathrm{N}$, et al. Effectiveness of subcutaneous immunotherapy for allergic rhinoconjunctivitis and asthma: a systematic review. Laryngoscope. 2014;124(3):616-27.

6. Roberts $\mathrm{G}$, et al. Grass pollen immunotherapy as an effective therapy for childhood seasonal allergic asthma. J Allergy Clin Immunol. 2006;117(2):263-8.

7. Antolin-Amerigo D, et al. Venom immunotherapy: an updated review. Curr Allergy Asthma Rep. 2014;14(7):449.

8. Mondoulet $L$, et al. Epicutaneous immunotherapy on intact skin using a new delivery system in a murine model of allergy. Clin Exp Allergy. 2010;40(4):659-67.

9. Oppenheimer JJ, et al. Treatment of peanut allergy with rush immunotherapy. J Allergy Clin Immunol. 1992;90(2):256-62.

10. Nelson HS, et al. Treatment of anaphylactic sensitivity to peanuts by immunotherapy with injections of aqueous peanut extract. J Allergy Clin Immunol. 1997:99(6 Pt 1):744-51.

11. Chiang D, Berin MC. An examination of clinical and immunologic outcomes in food allergen immunotherapy by route of administration. Curr Allergy Asthma Rep. 2015;15(6):536

12. Vazquez-Ortiz M, et al. Safety and predictors of adverse events during oral immunotherapy for milk allergy: severity of reaction at oral challenge, specific IgE and prick test. Clin Exp Allergy. 2013;43(1):92-102.

13. Virkud YV, et al. Novel baseline predictors of allergic side effects during peanut oral immunotherapy. J Allergy Clin Immunol. 2017;139(3):882888.e5. doi:10.1016/j.jaci.2016.07.030.

14. Berin MC, Mayer L. Can we produce true tolerance in patients with food allergy? J Allergy Clin Immunol. 2013;131(1):14-22.

15. Jones $\mathrm{SM}$, et al. Clinical efficacy and immune regulation with peanut oral immunotherapy. J Allergy Clin Immunol. 2009;124(2):292-300.

16. Cavkaytar O, Akdis CA, Akdis M. Modulation of immune responses by immunotherapy in allergic diseases. Curr Opin Pharmacol. 2014;17:30-7.

17. Dioszeghy $\vee$ et al. Differences in phenotype, homing properties and suppressive activities of regulatory T cells induced by epicutaneous, oral or sublingual immunotherapy in mice sensitized to peanut. Cell Mol Immunol. 2017:14(9):770-782. doi:10.1038/cmi.2016.14.

18. Vickery BP, et al. Peanut oral immunotherapy modifies IgE and IgG4 responses to major peanut allergens. J Allergy Clin Immunol. 2013;131(1):128-34.

19. Akdis CA, Akdis M. Mechanisms of allergen-specific immunotherapy and immune tolerance to allergens. World Allergy Organ J. 2015;8(1):17.

20. Leonard SA, et al. Oral immunotherapy induces local protective mechanisms in the gastrointestinal mucosa. J Allergy Clin Immunol. 2012;129(6):1579-87.

21. Berin C, Wang W. Oral immunotherapy in the sensitized mouse: barriers to tolerance induction. J Allergy Clin Immunol. 2010;125(2):Ab25

22. Syed $A$, et al. Peanut oral immunotherapy results in increased antigeninduced regulatory T-cell function and hypomethylation of forkhead box protein 3 (FOXP3). J Allergy Clin Immunol. 2014;133(2):500-10.

23. van Wijk F, et al. The effect of the food matrix on in vivo immune responses to purified peanut allergens. Toxicol Sci. 2005:86(2):333-41.

24. Schouten $B$, et al. Acute allergic skin reactions and intestinal contractility changes in mice orally sensitized against casein or whey. Int Arch Allergy Immunol. 2008;147(2):125-34

25. Li XM, et al. A murine model of IgE-mediated cow's milk hypersensitivity. J Allergy Clin Immunol. 1999;103(2 Pt 1):206-14.

26. Thyagarajan A, et al. Evidence of pathway-specific basophil anergy induced by peanut oral immunotherapy in peanut-allergic children. Clin Exp Allergy. 2012;42(8):1197-205.

27. Jutel $\mathrm{M}$, et al. Influence of bee venom immunotherapy on degranulation and leukotriene generation in human blood basophils. Clin Exp Allergy. 1996;26(10):1112-8

28. Xiang Z, Moller C, Nilsson G. Readministration of IgE is required for repeated passive cutaneous anaphylaxis in mice. Int Arch Allergy Immunol. 2006;141(2):168-71. 
29. Xiang Z, et al. IgE-mediated mast cell degranulation and recovery monitored by time-lapse photography. J Allergy Clin Immunol. 2001;108(1):116-21.

30. Van Ree $R$, et al. Measurement of IgE antibodies against purified grass pollen allergens (Lol p 1, 2, 3 and 5) during immunotherapy. Clin Exp Allergy. 1997;27(1):68-74.

31. Varshney $\mathrm{P}$, et al. A randomized controlled study of peanut oral immunotherapy: clinical desensitization and modulation of the allergic response. J Allergy Clin Immunol. 2011;127(3):654-60.

32. Burks AW, et al. Oral immunotherapy for treatment of egg allergy in children. N Engl J Med. 2012;367(3):233-43.

33. Rachid R, Umetsu DT. Immunological mechanisms for desensitization and tolerance in food allergy. Semin Immunopathol. 2012;34(5):689-702.

34. Suarez-Fueyo A, et al. Grass tablet sublingual immunotherapy downregulates the TH2 cytokine response followed by regulatory T-cell generation. J Allergy Clin Immunol. 2014;133(1):130-8.

35. Chehade M, Mayer L. Oral tolerance and its relation to food hypersensitivities. J Allergy Clin Immunol. 2005;115(1):3-12 (quiz 13).
36. Smit JJ, et al. Contribution of classic and alternative effector pathways in peanut-induced anaphylactic responses. PLoS ONE. 2011;6(12):e28917.

37. Shamji MH, Durham SR. Mechanisms of immunotherapy to aeroallergens. Clin Exp Allergy. 2011;41(9):1235-46.

38. Berin MC. Pathogenesis of IgE-mediated food allergy. Clin Exp Allergy. 2015;45(10):1483-96. doi:10.1111/cea.12598.

39. Jutel $\mathrm{M}$, et al. IL-10 and TGF-beta cooperate in the regulatory T cell response to mucosal allergens in normal immunity and specific immunotherapy. Eur J Immunol. 2003;33(5):1205-14.

40. Trinchieri G. Interleukin-10 production by effector T cells: Th1 cells show self control. J Exp Med. 2007;204(2):239-43.

41. Polukort SH, et al. IL-10 enhances IgE-mediated mast cell responses and is essential for the development of experimental food allergy in IL-10-deficient mice. J Immunol. 2016;196(12):4865-76.

42. Finkelman FD. Anaphylaxis: lessons from mouse models. J Allergy Clin Immunol. 2007;120(3):506-15 (quiz 516-7).

\section{Submit your next manuscript to BioMed Central and we will help you at every step:}

- We accept pre-submission inquiries

- Our selector tool helps you to find the most relevant journal

- We provide round the clock customer support

- Convenient online submission

- Thorough peer review

- Inclusion in PubMed and all major indexing services

- Maximum visibility for your research

Submit your manuscript at www.biomedcentral.com/submit 